\title{
Bisphosphonates and adipogenesis: Evidence for alendronate inhibition of adipocyte differentiation in 3T3-L1 preadipocytes through a vitamin D receptor mediated effect ${ }^{*}$
}

\author{
C. Mammi ${ }^{1 \#}$, M. Calanchini ${ }^{2}$, A. Antelmi ${ }^{1}$, A. Feraco ${ }^{1}$, L. Gnessi ${ }^{4}$, S. Falcone ${ }^{2}$, F. Quintarelli ${ }^{2}$, \\ G. M. Rosano ${ }^{1}$, A. Fabbri ${ }^{2}$, M. Caprio ${ }^{1}$

\footnotetext{
${ }^{1}$ Department of Medical Sciences, Centre of Clinical and Basic Research, IRCCS San Raffaele Pisana, Rome, Italy;

${ }^{\#}$ Corresponding Author: caterina.mammi@sanraffaele.it

${ }^{2}$ Unit of Endocrinology, S. Eugenio \& CTO A. Alesini Hospitals, Department of Internal Medicine, University of Rome "Tor Vergata", Rome, Italy

${ }^{3}$ Division of Endocrinology, Department of System Medicine, Section of Reproductive Endocrinology, University of TorVergata, Fatebenefratelli Hospital "San Giovanni Calibita", Rome, Italy

${ }^{4}$ Department of Experimental Medicine, Section of Medical Physiopathology and Endocrinology, Sapienza University of Rome, Rome, Italy
}

Received 14 May 2013; revised 14 June 2013; accepted 21 June 2013

Copyright (C) 2013 C. Mammi et al. This is an open access article distributed under the Creative Commons Attribution License, which permits unrestricted use, distribution, and reproduction in any medium, provided the original work is properly cited.

\section{ABSTRACT}

Background: Adipocyte and osteoblast derive from the same mesenchimal progenitor. Agerelated decrease in bone mass is accompanied by an increase in marrow adipose tissue. Vitamin D3 (VD3) inhibits adipogenesis in 3T3-L1 preadipocytes. Recently it has been demonstrated that alendronate (ALN) inhibits adipogenesis while promoting osteoblast differentiation of mesenchimal stem cells. Aim of the Study: To evaluate the role of ALN on adipocyte differentiation in vitro and the potential synergic role of VD3 co-treatment. Procedures: Murine 3T3-L1 and 3T3-F442A preadipocytes were routinely differentiated in presence of ALN and VD3 $10^{-9}$. $10^{-7} \mathrm{M}$ for 7 days and then stained with Oil Red $O$. The effect of these treatments on mRNA expression of the main molecular markers of adipocyte differentiation (PPARY and C/EBPa) and VD Receptor (VDR) were analyzed through RTPCR. Results: Both ALN and VD3 showed a marked anti-adipogenic effect on 3T3-L1 cells. Co-incubation of ALN $10^{-8} \mathrm{M}$ and VD3 $10^{-9} \mathrm{M}$ displayed no synergic effect on inhibition of adipogenesis. PPARy mRNA expression was significantly reduced by ALN and VD3. mRNA expression of C/EBPa was reduced only by VD3

*These authors equally contributed to this work. treatment. An increase in VDR mRNA expression of 3T3-L1 cells was observed with both ALN and VD3. On the contrary, 3T3-F442A cells, which are in a more advanced adipogenic differentiation stage compared to $3 \mathrm{~T} 3-\mathrm{L} 1$, did not express detectable levels of VDR. Interestingly, adipose differentiation of 3T3-F442A was not affected by ALN nor VD3. These results suggest that VDR may represent the molecular target of the antiadipogenic effect of ALN. Conclusion: VDR plays a critical role in mediating the anti-adipogenic effect of ALN. Further studies to clarify this mechanism are warranted.

Keywords: Alendronate; Adipogenesis; Vitamin D; Vitamin D Receptor; 3T3-L1; Mesenchimal Stem Cells

\section{INTRODUCTION}

Osteoporosis and fragility fractures represent a significant challenge for Health Systems in the western world because of their increasing number, a condition directly related to the steady growth of the elderly population. Around $40 \%$ of the population experience a femur, vertebrae or wrist fracture once in their lives, and in most cases this occurs after the age of 65 years.

Alendronate (ALN) is one of the most commonly used bisphosphonates (BP) for the treatment and prevention of 
osteoporosis [1]. BP most important biological effect is the reduction of bone remodelling through the regulation of osteoclastic activity. Recently it has been demonstrated that ALN inhibits adipogenesis while promoting osteoblast differentiation of mesenchimal stem cells (MSCs) [2]. Adipocyte and osteoblast are fenotipically well distinct mature cells that derive from the same mesenchimal progenitor [3-5].

MSCs have the potential to differentiate into cells of different lineages, including osteoblasts, adipocytes, chondrocytes and myocytes [3-5]. In particular there is a reciprocal relationship between the differentiation of adipocytes and osteoblasts [6]. The choice of a mesenchymal precursor cell to differentiate into a particular cell type is controlled by many environmental factors and the molecular mechanisms determining the differentiation towards the adipose or osteoblastic fate are still obscure.

Aging induces a decrease in the commitment of MSCs to the osteoblast lineage and an increase in the commitment to the adipocyte lineage [7,8]. Age-related osteoporosis exacerbates this phenomenon by increasing the proportion of adipocytes in the bone marrow $[9,10]$. Moreover, an inverse relationship between amount of trabecular bone and adipose tissue in bone marrow has been demonstrated [10,11]. Among preadipocyte cellular models, 3T3-L1 and 3T3-F442A cells represent the most valuable murine preadipocyte cell lines, which are isolated from the Swiss 3T3 cell line, derived from disaggregated 17to 19-day-old Swiss 3T3 mouse. Differently from 3T3L1, 3T3-F442A preadipocytes are in a more advanced differentiation stage, and for this reason they do not require an early commitment with glucocorticoids in order to undergo adipose differentiation.

1,25-Dihydroxyvitamin D3 (VD3) is a hormone that plays multiple physiological roles [12]. The classical function of VD3 is to regulate calcium and phosphorus homeostasis [13,14]. Low VD3 levels are major contributing factors to poor bone health and osteoporosis, and VD3 deficiency is highly prevalent worldwide [15]. Furthermore, VD3 regulates sulfate transport [16], the reninangiotensin system [17], the immune system [18], and organ development such as the mammary gland and skeletal muscle [19,20].

VD3 is a high-affinity ligand for the vitamin D receptor (VDR). VDRs are widely expressed in several tissues including vascular smooth muscle [21,22], endothelium $[23,24]$ and cardiomyocytes [25]. The ligand-activated VDR forms a heterodimer with the retinoid $\mathrm{X}$ receptor (RXR)- $\alpha$, a common heterodimeric partner for other class II nuclear receptors [26]. VDR-RXR heterodimer can bind to VD3 response elements in different genes causing the transactivation or repression of VD3 responsive genes in a variety of tissues [27].

VDR was detected in 3T3-L1 preadipocyte cells [28], one of the best characterized and widely used cellular model to study adipocyte differentiation [29]. To date, VDR expression has never been investigated in 3T3F442A cells (29). Several studies have shown that VD3 inhibits adipose differentiation of 3T3-L1 through the inhibition of the key adipogenesis transcription factors, such as peroxisome proliferator-activated receptor-gamma (PPAR $\gamma)$ and CCAAT/enhancer-binding proteins alfa $(\mathrm{C} / \mathrm{EBPa})[30,31]$. The nuclear receptor PPARg is a ligand-activated transcription factor that acts as a master regulator of adipogenesis, since it is both sufficient and necessary for conversion of pre-adipocytes into mature adipocytes. During adipogenesis, PPARg expression is enhanced by $\mathrm{C} / \mathrm{EBP} \alpha$ [32]. Finally, VD3 exerts an antiadipogenic effect in mouse bone marrow stromal cells [33].

Herein we evaluated the in vitro effects of ALN and its potential synergic role of concomitant treatment with VD3 in adipose differentiation of 3T3-L1 and 3T3F442A.

\section{MATERIALS AND METHODS}

\subsection{Cell Culture and Differentiation}

Murine 3T3-L1 and 3T3-F442A preadipocytes were grown until confluence at $37^{\circ} \mathrm{C}$ in Dulbecco's modified Eagle's medium (DMEM) (Invitrogen, Paisley, Scotland) containing $4.5 \mathrm{~g} /$ liter D-glucose, $10 \%$ fetal calf serum (FCS) (Invitrogen), 100 units/ml penicillin, and $100 \mu \mathrm{g} /$ $\mathrm{ml}$ streptomycin. After confluence 3T3-F442A adipose conversion was obtained in the same culture medium supplemented with $175 \mathrm{nM}$ insulin. 3T3-L1 adipocyte differentiation was initiated by the addition for $48 \mathrm{~h}$ at confluence of a cocktail containing $100 \mu \mathrm{M}$ 3-isobutyl-1methylxanthine (IBMX), $175 \mathrm{nM}$ insulin, and $100 \mathrm{nM}$ corticosterone or $250 \mathrm{nM}$ dexamethasone, in separate experiments. Cells were then refeed every 2 - 3 days by DMEM with $10 \%$ FCS and $175 \mathrm{nM}$ insulin.

After cell confluence ALN and VD3 (both purchased at Santa Cruz Biotechnology, Inc. CA. USA) was added to 3T3-L1 and 3T3-F442A cell cultures at concentrations between $10^{-9}$ and $10^{-7} \mathrm{M}$ for a period of 7 days.

\subsection{Morphological and Biochemical Determinations}

Cells were examined daily and observed under light microscopy and microphotography. For a morphological determination of cell lipid content, cells were fixed in $5 \%$ formaldehyde in phosphate-buffered saline (PBS), washed, then stained with oil red O. In some experiments, cells were permeabilized with $10 \%$ SDS and red oil staining was spectrophotometrically quantified at $520 \mathrm{~nm}$, after correction for cell number. 


\subsection{RNA Analysis and Real Time PCR}

Cells were washed twice with 1X PBS, harvested and immediately lysed in $1 \mathrm{ml}$ of TRIzol ${ }^{\mathrm{TM}}$ Reagent (Invitrogen). Total RNA was extracted following manufacturer's indications. The purity, integrity and yield of RNA were analyzed by Agilent Technologies 2001 bioanalyzer using the RNA 6000 LabChip kit. $1 \mu \mathrm{g}$ of total RNA was treated with DNAse I Amplification Grade (Invitrogen) and reverse-transcribed using the SuperScript ${ }^{\mathrm{TM}}$ III (Invitrogen). Quantitative PCR was performed in Mx3000$\mathrm{P}^{\mathrm{TM}}$ light cycler (Stratagene) using iTaqSupermix with rox (Biorad) as indicated by manufacturer. All primers peroxisome proliferators activated receptor $\gamma$ (PPAR $\gamma$ ), CCAAT/enhancer binding protein $\alpha(\mathrm{C} / \mathrm{EBP}-\alpha)$ and VDR were optimized for real-time RT-PCR amplification checking the generation of a single peak in a melting curve assay and the efficiency in standard curve amplification ( $>98 \%$ for each couple of primers). Quantitative RTPCR sample value was normalized for the expression of $18 \mathrm{~S}$ mRNA. The relative expression of investigated genes was calculated by $\mathrm{Mx} 3000 \mathrm{P}^{\mathrm{TM}}$ software version 2.0 (Stratagene) and is reported as arbitrary units. For all experiments each sample was analyzed in duplicate. Primer sequences used for real-time amplification are: $\mathrm{C} / \mathrm{EBP} \alpha$ primers: forward CTGCGAGCACGAGACGTCTATAG and reverse TCCCGGGTAGTCAAAGTCACC; PPAR $\gamma 2$ primers: forward GCATCAGGCTTCCACTATGGA and reverse GCACTTCTGAAACCGACA; VDR primers: forward CTGTGGCAGCCAAGACTACA and reverse GCAGCACATGTTCCTTCCTCA.

\subsection{Statistical Analysis}

Effects of VD3 and ALN on adipogenesis were assessed by a between-treatments factorial analysis of variance (ANOVA) including treatment effect, time effect, and their interactions. Pairwise comparisons were conducted by Tukey's or Dunnet's adjustment method of $\mathrm{P}$ values for more than three comparisons. Effects of other measurements were assessed with the same methodology. All analyses were performed using the GraphPad-Prism5 Software. P values of $<0.05$ were considered significant. Results are expressed as the means \pm standard error.

\section{RESULTS}

As previously reported [30,31] VD3 treatment showed a clear dose-dependent anti-adipogenic effect on 3T3-L1 cells (Figure 1). ALN induced a significant reduction in number and size of differentiation foci of cultured 3T3L1 cells, revealing a relevant anti-adipogenic effect $(\mathbf{F i}-$ gure 2). We kept using ALN at a concentration of $10^{-8} \mathrm{M}$. For co-incubation experiments, we chose concentrations of ALN of $10^{-8} \mathrm{M}$ and VD3 of $10^{-9} \mathrm{M}$.

Interestingly, co-incubation of 3T3-L1 cells with ALN

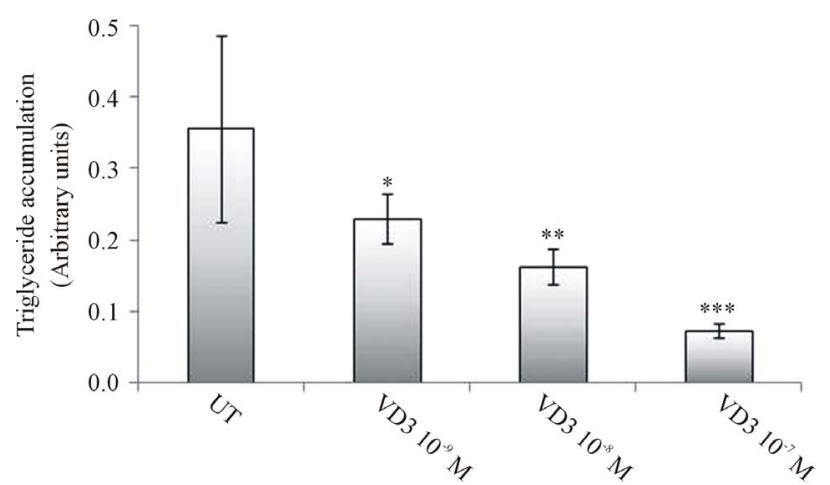

(a)
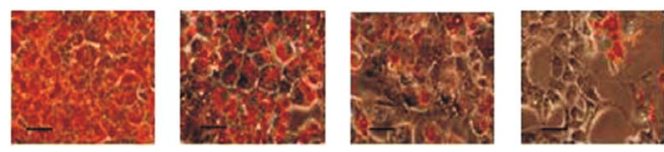

(b)

Figure 1. VD3 inhibitory effect on 3T3-L1 adipogenesis. (a) 3T3-L1 preadipocytes were induced to differentiate both in presence or absence of increasing concentration of VD3 $\left(10^{-9}\right.$. $10^{-7} \mathrm{M}$ ), then examined by microscopy after oil red $\mathrm{O}$ staining and tested for lipid accumulation, after 7 days. ${ }^{*} \mathrm{p}<0.05 ;{ }^{* *} \mathrm{p}<$ $0.01 ;{ }^{* * *} \mathrm{p}<0.001$; VD3-treated versus untreated cells (UT). (b) Representative microphotographs of the corresponding histograms shown in a (scale bar, $70 \mu \mathrm{m}$ ).

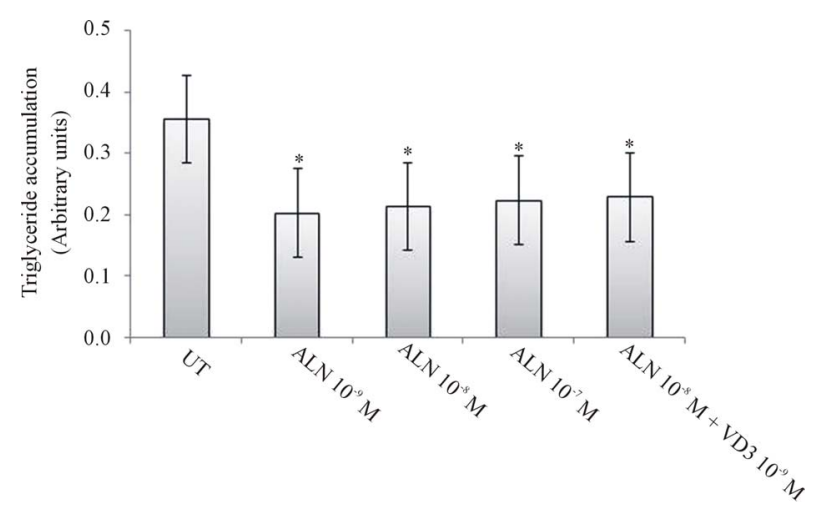

(a)
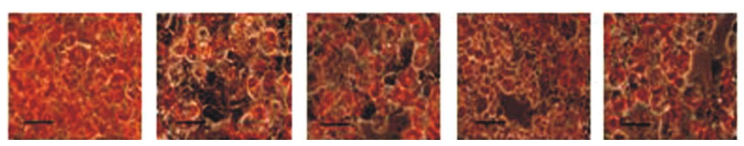

(b)

Figure 2. Inhibitory effect of ALN on 3T3-L1 differentiation. (a) 3T3-L1 preadipocytes were induced to differentiate in presence or in absence of increasing concentration of ALN $\left(10^{-9}-10^{-7} \mathrm{M}\right)$. Moreover 3T3-L1 were co-treated with ALN $10^{-8} \mathrm{M}$ and VD3 $10^{-9} \mathrm{M}$. After 7 days of differentiation, cells were examined by microscopy after oil red $\mathrm{O}$ staining and tested for lipid accumulation. ${ }^{*} \mathrm{p}<0.05$; ALN-treated versus untreated cells (UT). (b) Representative microphotographs of the corresponding histograms shown in (a) (scale bar, $70 \mu \mathrm{m}$ ).

$10^{-8} \mathrm{M}$ and VD3 $10^{-9} \mathrm{M}$ did not display any synergic effect in terms of inhibition of adipogenesis (Figure 2). 
PPAR $\gamma$ and $\mathrm{C} / \mathrm{EBP} \alpha$ are two crucial molecules for driving the transcriptional cascade that leads to adipocyte differentiation. The effect of ALN and VD3 treatments upon mRNA expression of PPAR $\gamma$ and $\mathrm{C} / \mathrm{EBP} \alpha$, and VDR, was analyzed through RT-PCR.

VD3 dose-dependently reduced PPAR $\gamma$ and $\mathrm{C} / \mathrm{EBP} \alpha$ mRNA expression reaching a marked suppression of both transcripts at a concentration of $10^{-7} \mathrm{M}$. ALN significantly reduced PPAR $\gamma$ mRNA expression and such effect was not dose-dependent (data not shown), on the contrary no significant effect on $\mathrm{C} / \mathrm{EBP} \alpha \mathrm{mRNA}$ expression was observed. Co-incubation of 3T3-L1 cells with ALN and VD3 did not display a significant synergic effect on both PPAR $\gamma$ and $\mathrm{C} / \mathrm{EBP} \alpha$ expression (Figure 3). In order to clarify the antiadipogenic role of ALN and VD3, we analysed transcript expression of VRD. Of relevance, an increase in VDR mRNA expression was ob-

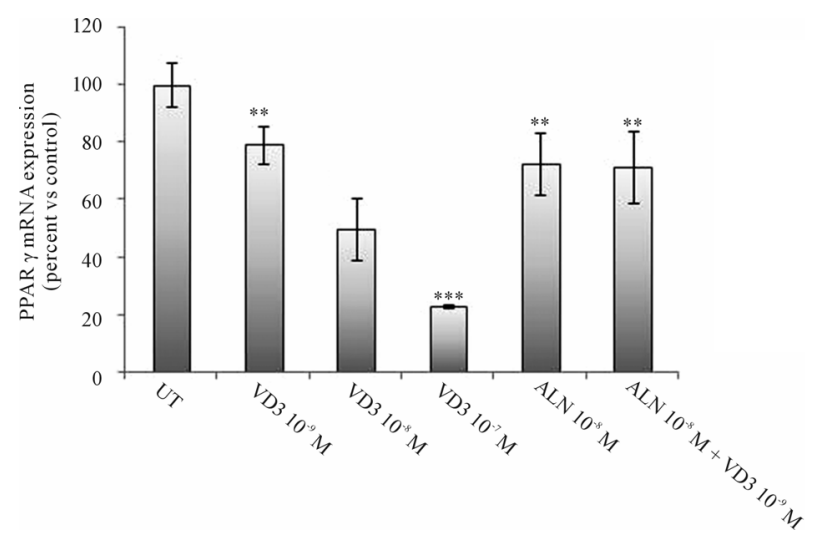

(a)

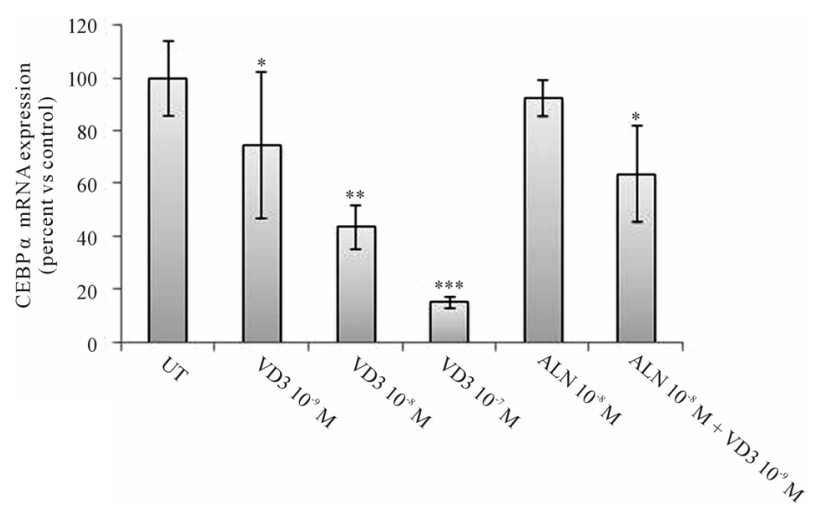

(b)

Figure 3. VD3 and ALN reduce the expression of key transcription factors of adipogenesis. 3T3-L1 at confluence were exposed to VD3 $\left(10^{-9}-10^{-7} \mathrm{M}\right)$, ALN $10^{-8}$ or co-treated with ALN $10^{-8}$ and VD3 $10^{-9} \mathrm{M}$. Total RNA was extracted at day 7 after starting of treatment and PPAR $\gamma$ (a) and C/EBP $\alpha$ (b) mRNA expression was measured by real time PCR. Results are expressed as percent of control untreated cells; mean \pm SEM of two independent experiments performed in duplicate. ${ }^{*} \mathrm{p}<0.05$; ${ }^{* *} \mathrm{p}<0.01 ;{ }^{* * *} \mathrm{p}<0.001$, drugs-exposed versus untreated cells (UT). served either with ALN or VD treatment, suggesting that VDR may represent the molecular target of the anti-adipogenic effect of ALN (Figure 4).

To address whether VDR is required in the inhibition of adipogenesis by ALN, we studied the effects of ALN and VD3 on 3T3-F442A cells, a cell line in a more advanced differentiation stage towards adipogenesis compared to 3T3-L1 cell line. Previous studies showed that preadipocyte 3T3-L1 cells do not express VDR. However, high levels of VDR are expressed within the first 4 hours of differentiation while VDRs decrease back to baseline levels within 24 hours after adipogenic induction [30].

Accordingly, we found that the expression of VDR mRNA in 3T3-F442A cells was significantly lower than in 3T3-L1 (Figure 5(a)) and VDR mRNA expression in 3T3-F442A markedly decreased during the early stages of differentiation (Figure 5(b)); thus 3T3-F442A cells represent a suitable model to study the role of VDR in mediating the effects of ALN. Remarkably, adipose differentiation of 3T3-F442A cells was not affected by both ALN and VD3 (Figure 6).

\section{DISCUSSION}

To counteract the increasing commitment of bone MSCs to the adipocyte lineage in the osteoporosis condition, a promising approach relies on the characterization of the complex molecular mechanism regulating cell commitment towards the adipogenic or osteoblastic lineage.

ALN is usually known to act selectively on osteoclastic activity inhibition and is the most commonly used

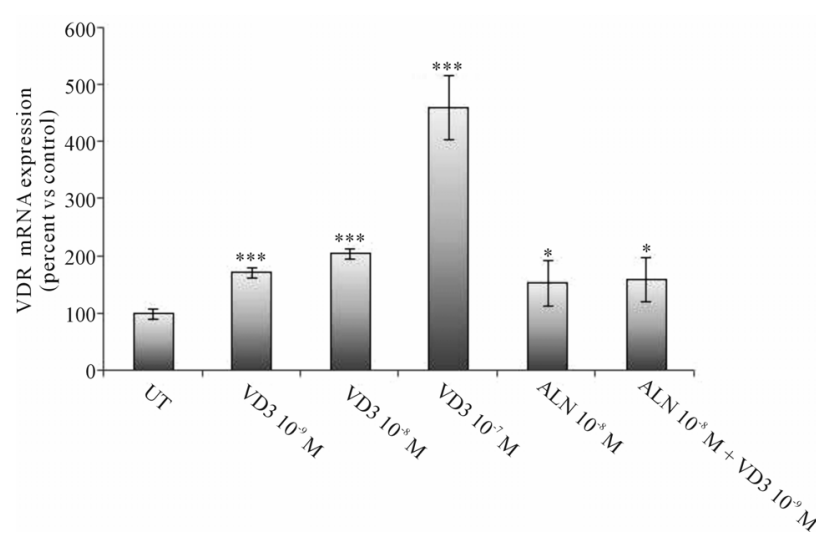

Figure 4. VD3 and ALN increase the expression of VDR. 3T3$\mathrm{L} 1$ at confluence were exposed to $\operatorname{VD} 3\left(10^{-9}-10^{-7} \mathrm{M}\right)$, ALN $10^{-8}$ or co-treated with ALN $10^{-8}$ and VD3 $10^{-9} \mathrm{M}$ for 7 days. At the end of the treatment period, total RNA was extracted and VDR mRNA expression was measured by real time PCR. Results are expressed as percent of control untreated cells; mean \pm SEM of two independent experiments performed in duplicate. ${ }^{*} \mathrm{p}<0.05 ;{ }^{* * *} \mathrm{p}<0.001$, drugs-exposed versus untreated cells (UT). 


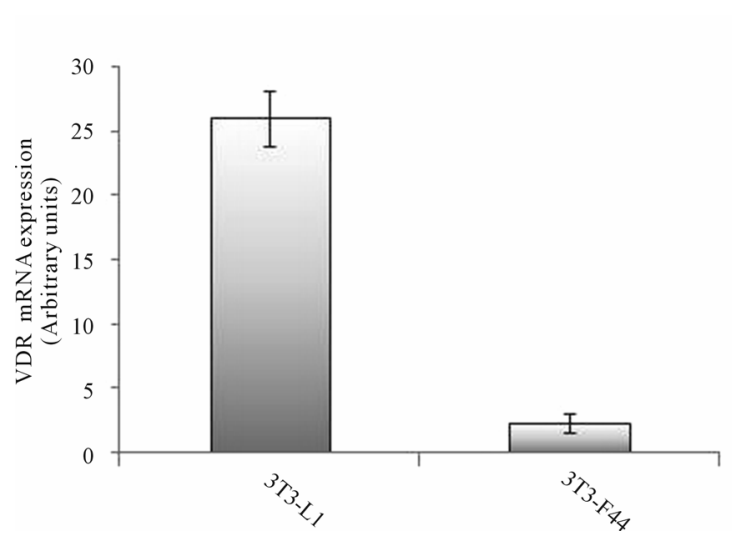

(a)

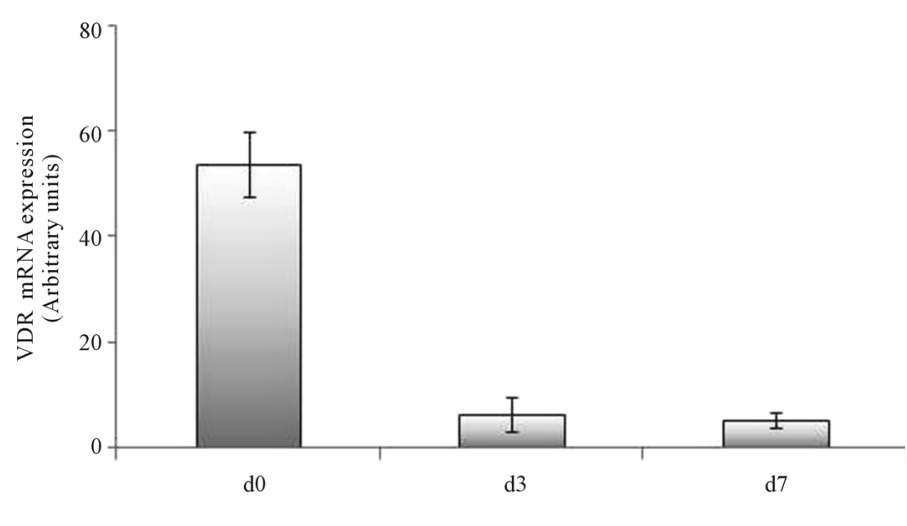

(b)

Figure 5. VDR mRNA expression in 3T3-L1 and 3T3-F442A cells. (a) mRNA expression of VDR after 7 days of differentiation of 3T3-L1 and 3T3-F442A preadipocytes. VDR mRNA was measured by real time PCR. (b) levels of VDR mRNA expression in 3T3-F442A measured at different adipogenic stages [confluence (d0), day $3(\mathrm{~d} 3)$, day 7 (d7)].

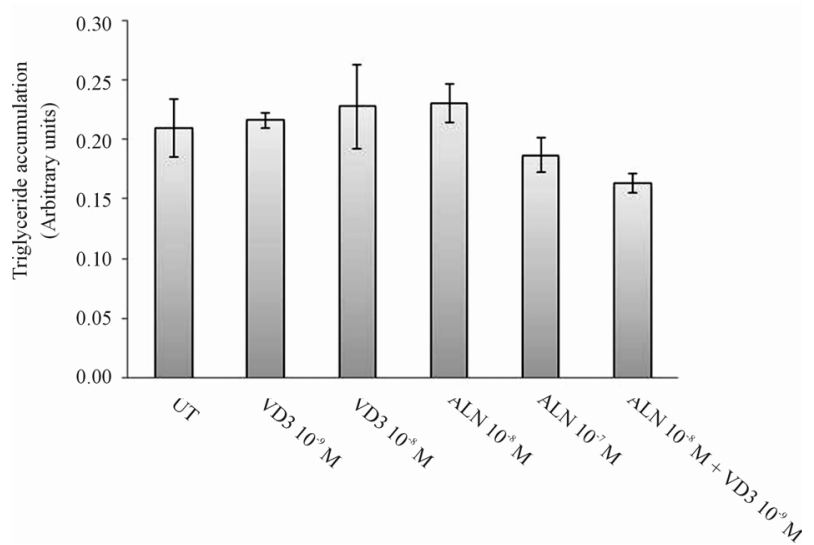

Figure 6. Effect of ALN and VD3 on 3T3-F442A differentiation. 3T3-F442A preadipocytes were induced to differentiate in presence or in absence of increasing concentration of ALN (from $10^{-9}$ to $10^{-7} \mathrm{M}$ ). Moreover 3T3-F442A cells were cotreated with ALN $10^{-8} \mathrm{M}$ and VD3 $10^{-9} \mathrm{M}$. After 7 days of differentiation, cells were examined by microscopy after oil red O staining and tested for lipid accumulation.

antiresorptive treatment for osteoporosis, displaying a specific efficacy in the elderly [6]. In order to achieve maximal benefit from ALN therapy, VD3 status should be investigated and association of ALN with VD3 supplementation is frequently required in older people, mostly due to age-related decreased capacity of human skin to produce VD3 [34]. An essential mechanism inducing bone mass reduction, especially in older adults, is the shift in bone marrow MSCs differentiation towards adipogenesis instead of osteoblastogenic lineage [8,35]. There is increasing evidence that ALN, in addition to its direct effects on osteoclasts, has an anabolic effect promoting the stimulation of osteoblastogenesis $[2,36]$. Furthermore, in vitro MSCs treatment with ALN displays an anabolic effect not only through the induction of osteoblastogenesis but also through the inhibition of adipoge- nesis [2].

In the present work we investigated the ALN effect on 3T3-L1 cells, a valuable model to study adipocyte development [29]. We identified for the first time a significant anti-adipogenic effect of ALN on 3T3-L1. Such effect was remarkably similar to the anti-adipogenic effect obtained with VD3 treatment. Moreover, we showed that the ALN-induced inhibition of adipogenesis was mediated by a reduction in PPAR $\gamma$ mRNA levels. Likewise, VD3 reduced PPAR $\gamma$ mRNA expression in 3T3-L1 cells. It is known that the adipogenic program in adipocyte precursors requires a sequential series of gene expression events and specific molecular factors are critical during each phase of differentiation. PPAR $\gamma$ activation plays a central role in initiating adipogenesis [37,38]. In vitro studies demonstrate that several PPAR $\gamma$ ligands induce murine bone MSCs adipose differentiation and inhibit osteogenesis $[39,40]$.

In our experiments ALN and VD3 co-treatment did not display synergic anti-adipogenic effect on 3T3-L1 cells. The convergence of the molecular pathways activated by the two ligands towards the same transcriptional regulator of adipogenesis, PPAR $\gamma$ may explain this phenomenon. On the contrary, we observed no variation in $\mathrm{C} /$ EBP $\alpha$ mRNA expression after ALN treatment, suggesting that PPAR $\gamma$ is the main target of the inhibitory effect of ALN [41].

Furthermore, we focused on VDR mRNA expression in 3T3-L1 cells treated with ALN and VD3. The induction of VDR early in the adipogenic program is noteworthy. VDR is expressed in a peculiar transient manner: VDR mRNA levels are present only during the first $24 \mathrm{~h}$ and at one of the highest levels recorded for a nuclear receptor mRNA $[42,43]$. Likewise VDR, other nuclear receptors like glucocorticoid receptor, mineralocorticoid receptor and RXR show transient expression during adi- 
pogenesis $[44,45]$. Of relevance, $\mathrm{RXR} \alpha$ is the common heterodimeric partner of both VDR and PPAR $\gamma$, and RXR $\alpha$ levels in 3T3-L1 cells are very low in the early stages of adipogenesis and gradually increase after adipogenic induction $[30,42,46]$.

In the present study we confirmed that VD3 treatment increased VDR mRNA expression in 3T3-L1 after 7 days of adipose differentiation [30]. Interestingly, we found that also ALN treatment increased VDR mRNA expression. The finding of a similar effect of VD3 and ALN on VDR expression suggests that ALN inhibits adipocyte differentiation in 3T3-L1 through a VDR mediated effect.

To confirm this hypothesis we investigated VDR mRNA in terminally differentiated3T3-F442A, a cell model in a more advanced stage of adipogenesis compared to 3T3-L1 [29]. We observed that VDR mRNA expression was remarkably lower in differentiated 3T3F442A than in 3T3-L1 cells and that VDR mRNA expression in 3T3-F442A was markedly decreased during the early stages of adipogenesis.

Therefore 3T3-F442A cells are a suitable model to study the role of VDR in mediating the anti-adipogenic effect of ALN and VD3. Adipose differentiation of 3T3F442A cells was not affected neither by ALN nor by VD3. Thus, our data represent an indirect evidence of the role of VDR in mediating the anti-adipogenic effect of VD3 and ALN.

One possible explanation for this behaviour is that the increased mRNA VDR levels, induced by both VD3 and ALN treatment, might sequester RXR away from PPAR $\gamma$ binding in the early stage of adipogenesis, when PPAR $\gamma$ is crucial to start the differentiation program. The biological significance of the VDR pattern of expression during adipogenesis in presence of VD3 and ALN requires further investigation.

\section{CONCLUSION}

The importance of better understanding the mechanisms that reduce the risk of fracture is evident, both from an individual and a social perspective. Modulation of cell phenotype opens opportunities for preventive and interventional therapies to address the growing problem of osteoporosis in the aging population. We hypothesize that exposure to adequate amounts of VD3 could attenuate the increase of marrow adipose tissue in the aging bone and we envisage a new role of ALN in preserving bone mass. Of course such challenging hypothesis requires further studies, both in animal and clinical settings.

\section{ACKNOWLEDGEMENTS}

This work has been supported by institutional funding from the Uni- versity of Rome Tor Vergata (Progetti Ricerca Interesse Nazionale Ministero dell'Università e della Ricerca 2009), from institutional fundings of IRCCS San Raffaele Pisana (Ricerca Corrente), and from a spontaneous research grant of Merck.

\section{REFERENCES}

[1] Wells, G. A., Cranney, A., Peterson, J., Boucher, M., Shea, B., Robinson, V., Coyle, D. and Tugwell, P. (2008) Alendronate for the primary and secondary prevention of osteoporotic fractures in postmenopausal women. Cochrane database of Systematic Reviews, CD001155.

[2] Duque, G. and Rivas, D. (2007) Alendronate has an anabolic effect on bone through the differentiation of mesenchymal stem cells. Journal of Bone and Mineral Research, 22, 1603-1611. doi:10.1359/jbmr.070701

[3] Nuttall, M.E. and Gimble, J.M. (2000) Is there a therapeutic opportunity to either prevent or treat osteopenic disorders by inhibiting marrow adipogenesis? Bone, 27, 177-184. doi:10.1016/S8756-3282(00)00317-3

[4] Nuttall, M.E. and Gimble, J.M. (2004) Controlling the balance between osteoblastogenesis and adipogenesis and the consequent therapeutic implications. Current Opinion in Pharmacology, 4, 290-294. doi:10.1016/i.coph.2004.03.002

[5] Sambrook, P. and Cooper, C. (2006) Osteoporosis. Lancet, 367, 2010-2018. doi:10.1016/S0140-6736(06)68891-0

[6] Melo, M., Qiu, F., Sykora, K., Juurlink, D., Laupacis, A. and Mamdani, M. (2006) Persistence with bisphosphonate therapy in older people. Journal of the American Geriatrics Society, 54, 1015-1016. doi:10.1111/j.1532-5415.2006.00758.x

[7] Still, K., Phipps, R.J. and Scutt, A. (2003) Effects of risedronate, alendronate, and etidronate on the viability and activity of rat bone marrow stromal cells in vitro. Calcified Tissue International, 72, 143-150. doi:10.1007/s00223-001-2066-y

[8] Gimble, J.M., Zvonic, S., Floyd, Z.E., Kassem, M. and Nuttall, M.E. (2006) Playing with bone and fat. Journal of Cellular Biochemistry, 98, 251-266. doi:10.1002/jcb. 20777

[9] Vost, A. (1963) Osteoporosis: A necropsy study of vertebrae and iliac crests. American Journal of Pathology, 43, 143-151.

[10] Pittenger, M.F., Mackay, A.M., Beck, S.C., Jaiswal, R.K., Douglas, R., Mosca, J.D., Moorman, M.A., Simonetti, D.W., Craig, S. and Marshak, D.R. (1999) Multilineage potential of adult human mesenchymal stem cells. Science, 284, 143-147. doi:10.1126/science.284.5411.143

[11] David, V., Martin, A., Lafage-Proust, M.H., Malaval, L., Peyroche, S., Jones, D.B., Vico, L. and Guignandon, A. (2007) Mechanical loading down-regulates peroxisome proliferator-activated receptor gamma in bone marrow stromal cells and favors osteoblastogenesis at the expense of adipogenesis. Endocrinology, 148, 2553-2562. doi:10.1210/en.2006-1704

[12] Sutton, A.L. and MacDonald, P.N. (2003) Vitamin D: More than a "bone-a-fide" hormone. Molecular Endocri- 
nology, 17, 777-791. doi:10.1210/me.2002-0363

[13] Dusso, A.S., Brown, A.J. and Slatopolsky, E. (2005) Vitamin D. Renal Physiology: American Journal of Physiology, 289, F8-F28. doi:10.1152/ajprenal.00336.2004

[14] Jones, G., Strugnell, S.A. and DeLuca, H.F. (1998) Current understanding of the molecular actions of vitamin $\mathrm{D}$. Physiological Reviews, 78, 1193-1231.

[15] Holick, M.F. (2006) High prevalence of vitamin D inadequacy and implications for health. Mayo Clinic Proceedings, 81, 353-373. doi:10.4065/81.3.353

[16] Bolt, M.J., Liu, W., Qiao, G., Kong, J., Zheng, W., Krausz, T., Cs-Szabo, G., Sitrin, M.D. and Li, Y.C. (2004) Critical role of vitamin D in sulfate homeostasis: Regulation of the sodium-sulfate cotransporter by 1,25-dihydroxy-vitamin D3. Endocrinology and Metabolism: American Journal of Physiology, 287, E744-E749. doi:10.1152/ajpendo.00151.2004

[17] Li, Y.C., Kong, J., Wei, M., Chen, Z.F., Liu, S.Q. and Cao, L.P. (2002) 1,25-Dihydroxyvitamin $\mathrm{D}(3)$ is a negative endocrine regulator of the renin-angiotensin system. Journal of Clinical Investigation, 110, 229-238.

[18] Mathieu, C. and Adorini, L. (2002) The coming of age of 1,25-dihydroxyvitamin $\mathrm{D}(3)$ analogs as immunomodulatory agents. Trends in Molecular Medicine, 8, 174-179. doi:10.1016/S1471-4914(02)02294-3

[19] Endo, I., Inoue, D., Mitsui, T., Umaki, Y., Akaike, M., Yoshizawa, T., Kato, S. and Matsumoto, T. (2003) Deletion of vitamin $\mathrm{D}$ receptor gene in mice results in abnormal skeletal muscle development with deregulated expression of myoregulatory transcription factors. Endocrinology, 144, 5138-5144. doi:10.1210/en.2003-0502

[20] Zinser, G., Packman, K. and Welsh, J. (2002) Vitamin D(3) receptor ablation alters mammary gland morphogenesis. Development, 129, 3067-3076.

[21] Merke, J., Hofmann, W., Goldschmidt, D. and Ritz, E. (1987) Demonstration of 1,25(OH)2 vitamin D3 receptors and actions in vascular smooth muscle cells in vitro. Calcified Tissue International, 41, 112-114. doi:10.1007/BF02555253

[22] Somjen, D., Weisman, Y., Kohen, F., Gayer, B., Limor, R., Sharon, O., Jaccard, N., Knoll, E. and Stern, N. (2005) 25-hydroxyvitamin D3-1alpha-hydroxylase is expressed in human vascular smooth muscle cells and is upregulated by parathyroid hormone and estrogenic compounds. Circulation, 111, 1666-1671. doi:10.1161/01.CIR.0000160353.27927.70

[23] Merke, J., Milde, P., Lewicka, S., Hugel, U., Klaus, G., Mangelsdorf, D.J., Haussler, M.R., Rauterberg, E.W. and Ritz, E. (1989) Identification and regulation of 1,25-dihydroxyvitamin D3 receptor activity and biosynthesis of 1,25-dihydroxyvitamin D3. Studies in cultured bovine aortic endothelial cells and human dermal capillaries. Journal of Clinical Investigation, 83, 1903-1915. doi:10.1172/JCI114097

[24] Caprio, M., Mammi, C. and Rosano, G.M. (2012) Vitamin D: a novel player in endothelial function and dysfunction. Archives of Medical Science, 8, 4-5. doi:10.5114/aoms.2012.27271

[25] O’Connell, T.D., Berry, J.E., Jarvis, A.K., Somerman, M.J. and Simpson, R.U. (1997) 1,25-Dihydroxyvitamin D3 regulation of cardiac myocyte proliferation and hypertrophy. American Journal of Physiology, 272, H1751H1758.

[26] Mangelsdorf, D.J. and Evans, R.M. (1995) The RXR heterodimers and orphan receptors. Cell, 83, 841-850. doi:10.1016/0092-8674(95)90200-7

[27] Haussler, M.R., Whitfield, G.K., Haussler, C.A., Hsieh, J.C., Thompson, P.D., Selznick, S.H., Dominguez, C.E. and Jurutka, P.W. (1998) The nuclear vitamin D receptor: Biological and molecular regulatory properties revealed. Journal of Bone and Mineral Research, 13, 325-349. doi:10.1359/jbmr.1998.13.3.325

[28] Sato, M. and Hiragun, A. (1988) Demonstration of 1 alpha,25-dihydroxyvitamin D3 receptor-like molecule in ST 13 and 3T3 L1 preadipocytes and its inhibitory effects on preadipocyte differentiation. Journal of Cellular Physiology, 135, 545-550. doi:10.1002/jcp.1041350326

[29] Armani, A., Mammi, C., Marzolla, V., Calanchini, M., Antelmi, A., Rosano, G.M., Fabbri, A. and Caprio, M. (2010) Cellular models for understanding adipogenesis, adipose dysfunction, and obesity. Journal of Cellular Biochemistry, 110, 564-572. doi:10.1002/jcb.22598

[30] Kong, J. and Li, Y.C. (2006) Molecular mechanism of 1,25-dihydroxyvitamin D3 inhibition of adipogenesis in 3T3-L1 cells. Endocrinology and Metabolism: American Journal of Physiology, 290, E916-E924. doi:10.1152/ajpendo.00410.2005

[31] Blumberg, J.M., Tzameli, I., Astapova, I., Lam, F.S., Flier, J.S. and Hollenberg, A.N. (2006) Complex role of the vitamin D receptor and its ligand in adipogenesis in 3T3-L1 cells. The Journal of Biological Chemistry, 281, 1120511213. doi:10.1074/jbc.M510343200

[32] Rosen, E.D. (2005) The transcriptional basis of adipocyte development. Prostaglandins, Leukotrienes and Essential Fatty Acids, 73, 31-34. doi:10.1016/j.plefa.2005.04.004

[33] Kelly, K.A. and Gimble, J.M. (1998) 1,25-Dihydroxy vitamin D3 inhibits adipocyte differentiation and gene expression in murine bone marrow stromal cell clones and primary cultures. Endocrinology, 139, 2622-2628. doi:10.1210/en.139.5.2622

[34] MacLaughlin, J. and Holick, M.F. (1985) Aging decreases the capacity of human skin to produce vitamin D3. Journal of Clinical Investigation, 76, 1536-1538. doi:10.1172/JCI112134

[35] Chan, G.K. and Duque, G. (2002) Age-related bone loss: Old bone, new facts. Gerontology, 48, 62-71. doi:10.1159/000048929

[36] Chavassieux, P.M., Arlot, M.E., Reda, C., Wei, L., Yates, A.J. and Meunier, P.J. (1997) Histomorphometric assessment of the long-term effects of alendronate on bone quality and remodeling in patients with osteoporosis. Journal of Clinical Investigation, 100, 1475-1480. doi:10.1172/JCI119668

[37] Rosen, E.D. and MacDougald, O.A. (2006) Adipocyte differentiation from the inside out. Nature Reviews Molecular Cell Biology, 7, 885-896. doi: $10.1038 / \mathrm{nrm} 2066$

[38] Tzameli, I., Fang, H., Ollero, M., Shi, H., Hamm, J.K., 
Kievit, P., Hollenberg, A.N. and Flier, J.S. (2004) Regulated production of a peroxisome proliferator-activated receptor-gamma ligand during an early phase of adipocyte differentiation in 3T3-L1 adipocytes. The Journal of Biological Chemistry, 279, 36093-36102. doi:10.1074/jbc.M405346200

[39] Gimble, J.M., Robinson, C.E., Wu, X., Kelly, K.A., Rodriguez, B.R., Kliewer, S.A., Lehmann, J.M. and Morris, D.C. (1996) Peroxisome proliferator-activated receptorgamma activation by thiazolidinediones induces adipogenesis in bone marrow stromal cells. Molecular Pharmacology, 50, 1087-1094.

[40] Lecka-Czernik, B., Moerman, E.J., Grant, D.F., Lehmann, J.M., Manolagas, S.C. and Jilka, R.L. (2002) Divergent effects of selective peroxisome proliferator-activated receptor-gamma 2 ligands on adipocyte versus osteoblast differentiation. Endocrinology, 143, 2376-2384. doi:10.1210/en.143.6.2376

[41] Rosen, E.D., Hsu, C.H., Wang, X., Sakai, S., Freeman, M. W., Gonzalez, F.J. and Spiegelman, B.M. (2002) C/EBPalpha induces adipogenesis through PPARgamma: A unified pathway. Genes \& Development, 16, 22-26. doi:10.1101/gad.948702

[42] Fu, M., Sun, T., Bookout, A.L., Downes, M., Yu, R.T., Evans, R.M. and Mangelsdorf, D.J. (2005) A nuclear re0 ceptor atlas: 3T3-L1 adipogenesis. Molecular Endocrinology, 19, 2437-2450. doi:10.1210/me.2004-0539

[43] Imagawa, M., Tsuchiya, T. and Nishihara, T. (1999) Identification of inducible genes at the early stage of adipocyte differentiation of 3T3-L1 cells. Biochemical and Biophysical Research Communications, 254, 299-305. doi:10.1006/bbrc.1998.9937

[44] Marzolla, V., Armani, A., Zennaro, M. C., Cinti, F., Mammi, C., Fabbri, A., Rosano, G.M. and Caprio, M (2012) The role of the mineralocorticoid receptor in adipocyte biology and fat metabolism. Molecular and Cellular Endocrinology, 350, 281-288. doi:10.1016/j.mce.2011.09.011

[45] Caprio, M., Antelmi, A., Chetrite, G., Muscat, A., Mammi, C., Marzolla, V., Fabbri, A., Zennaro, M.C. and Feve, B. (2011) Antiadipogenic effects of the mineralocorticoid receptor antagonist drospirenone: Potential implications for the treatment of metabolic syndrome. Endocrinology, 152, 113-125. doi:10.1210/en.2010-0674

[46] Burton, G.R., Guan, Y., Nagarajan, R. and McGehee, R.E., Jr. (2002) Microarray analysis of gene expression during early adipocyte differentiation. Gene, 293, 21-31. doi:10.1016/S0378-1119(02)00726-6 